\title{
Enhancement of Biogas Production Potential for Anaerobic Co-digestion of Wastewater using Decanter Cake
}

\author{
Thaniya Kaosol and Narumol Sohgrathok \\ Department of Civil Engineering, Environmental Engineering Program, \\ Faculty of Engineering, Prince of Songkla University, Songkhla, 90110, Thailand
}

Received 2012-10-23, Revised 2012-10-23; Accepted 2013-03-15

\begin{abstract}
The wastewater from agro-industry treated with the biological treatment cannot produce the biogas because of its low COD level and its low organic content. In this research, the co-digestion with decanter cake will improve the biogas yield and biogas production of wastewater. The effect of three parameters (i.e., type of wastewater, mixing and mesophilic temperature) will be evaluated in batch digesters under anaerobic condition. Moreover, the study determines the biogas production potential of several mixtures and that of wastewater alone. The co-digestion of decanter cake with rubber block wastewater of the R4 (wastewater $200 \mathrm{ml}$ with decanter cake $8 \mathrm{~g}$ ) produces the highest biogas yield $3,809 \mathrm{~mL} \mathrm{CH}_{4} / \mathrm{g}$ COD removal and the percentage maximum methane gas is $66.7 \%$. The experimental result shows that the mixing and mesophilic temperature have no significant effect on the biogas potential production. The co-digestion of decanter cake with rubber block wastewater provides the highest biogas yield potential production in the ambient temperature. The experimental results reveal that the decanter cake can be potential sources for biogas production.
\end{abstract}

Keywords: Decanter Cake, Anaerobic Co-Digestion, Palm Oil Mill Industry, Biogas, Wastewater

\section{INTRODUCTION}

Biochemical methane potential test can determine the methane yield of an organic matter substrate by anaerobic digestion under specific condition and media. The BMP test was initially developed in the seventies (Owen et al., 1979). Several studies in the 1970s reported the Biochemical Methane Potential (BMP) of crop species, wastes and other forms of biomass (Gunaseelan, 1997). The BMP test is widely applied to determine the anaerobic biodegradability of wastes. Also, the BMP test is a common parameter for waste characterization to determine the quantity of methane (1 methane/g COD removed) that the waste can potentially produce in anaerobic conditions (Angelidaki et al., 2009; Kirkeby et al., 2006).

A Biochemical Methane Potential (BMP) assay provides a measure of an anaerobic digestibility of a given substrate. The use of BMPs provides a relatively inexpensive and repeatable method for relative comparisons of the anaerobic digestibility and potential biogas production among various substrates. The BMP can be used to determine the amount of organic carbon in a given material that can be anaerobically converted to methane. Thus, the BMP can evaluate the potential biogas production efficiency of the anaerobic process on a given material. The BMP assay process was first established by Owen et al. (1979) as a simple and inexpensive procedure to monitor relative anaerobic biodegradability of substrate.

In Thailand, a "Strategic plan for renewable energy development" has been established since 2003. It aims to increase the share of renewable energy to 19,700 ktoe per year, by the year 2022 (Paepatung et al., 2009). Source of biogas production in Thailand cover a wide range of feedstocks including animal wastes, household

Corresponding Author: Thaniya Kaosol, Department of Civil Engineering, Environmental Engineering Program,

Faculty of Engineering, Prince of Songkla University, Songkhla, 90110, Thailand 
wastes, crop residues, sewage sludge, wastewater, industrial waste, agro-industrial waste and landfill (Pipatmanomai et al., 2009). The anaerobic digestion of biomass feedstock or the organic waste from factory is widely recognized as a mature and cost-effective process for producing biogas, which is a valuable renewable primary-energy source. Increasing interests in renewable energy production and in reduction of the greenhouse gas emissions associated with fossil fuels has made anaerobic digestion of plant biomass an attractive option.

Biogas can be categorized as one solution for this renewable energy promotion scheme as well as an alternative for reduction of greenhouse gases emissions. Biogas, a clean and renewable from of energy can be a good substitution of conventional sources of energy (fossil fuels, oil) which are causing ecologicalenvironmental problems and at the same time depleting at a faster rate (Yadvika et al., 2004). Biogas is the combustible gas produced through an anaerobic digestion at low-temperature and without oxygen. Thus, its application includes electricity, heating and cooking.

Biogas is a product of anaerobic degradation of organic substrates, which is one of the oldest processes used for the treatment of agro-industry wastes. Normally, the anaerobic fermentation is a slow process. In conventional biogas plants, a large HRT of 30-50 days is used. However, this slow process leads to a large volume of the digester and hence high cost of the system. Typically, the biogas from anaerobic digestion consists of $55-80 \%$ Methane gas, $20-45 \%$ Carbon dioxide, less than 3\% Hydrogen sulfide with trace amount of Ammonia and other impurities (Truong and Abatzoglou, 2005; Koblitsch et al., 2008).

Palm oil mills produce significant quantities of wastes such as empty fruit bunches, decanter cake, cake slurry, shell, fibers and ash from boilers. These wastes could reduce environmental and lifestyle qualities in nearby communities (Yahya et al., 2010). Decanter cake is an agro-industry waste from palm oil mill industry. Decanter cake was estimated to be 0.27 million tons a year (Chavalparit et al., 2006). Decanter cake is currently utilized as fertilizers and soil cover materials in palm oil plantation areas. The low waste load of decanter cake in each factory may not be sufficient to make a biogas plant cost-effective.

An interesting option for improving yields of anaerobic digestion of solid wastes is co-digestion. The benefits of co-digestion include: dilution of potential toxic compounds, improving balance of nutrients, synergistic effect of microorganisms, increasing load of biodegradable organic matter and better biogas yield. Addition advantages include hygienic stabilization and increased digestion rate (Sosnowski et al., 2003). Codigestion of different materials may enhance the anaerobic digestion process due to better carbon and nutrient balance (Yen and Brune, 2007; Parawira et al., 2007). Thus, co-digestion of decanter cake with other wastewater offers some interesting alternative such as, decanter cake co-digestion with frozen food wastewater and rubber block wastewater.

In this study, the biogas yield of decanter cake and wastewater as co-anaerobic digestion is evaluated using the BMP test. The biogas and methane gas will be analyzed daily to determine the effect of the coanaerobic digestion. Two wastewater sources (i.e., frozen seafood industry and rubber block industry) will be used to co-digest with the decanter cake. Additionally, different operating conditions are also evaluated.

\section{MATERIALS AND METHODS}

\subsection{Raw Materials}

Decanter cake is obtained from a palm oil mill industry in Krabi province (Fig. 1). Frozen seafood wastewater is obtained from a frozen seafood industry in Songkhla province. Rubber block wastewater is obtained from a rubber block industry in Songkhla province also. Elemental composition of substrates expressed as Carbon, Hydrogen, Nitrogen and Sulfur (CHNS) dry weight content was determined by means of Elemental Analyzer. The oxygen content was calculated.

\subsection{Experimental Setup}

The BMP test is conducted using the method of Owen et al. (1979). Duplicate bottles are assayed by BMP using various concentrations of decanter cake and the amount of wastewater sample of $200 \mathrm{~mL}$. A working volume of $200 \mathrm{~mL}$ is used in each serum vial. The vials are flushed with nitrogen gas before sealing. All cumulative biogas production is measured via water displacement method. All experiments are run in duplicates. Two parameters are evaluated including (1) varying type of wastewater and (2) varying operating condition.

\subsection{BMP Assay}

The BMP assays are conducted in $250 \mathrm{~mL}$ serum bottles with rubber stoppers which are filled with the volumes of inoculums and substrate. Nitrogen gas is used in flushing over the headspace for $2 \mathrm{~min}$ to remove traces of oxygen to insure anaerobic conditions (Fig. 2). 


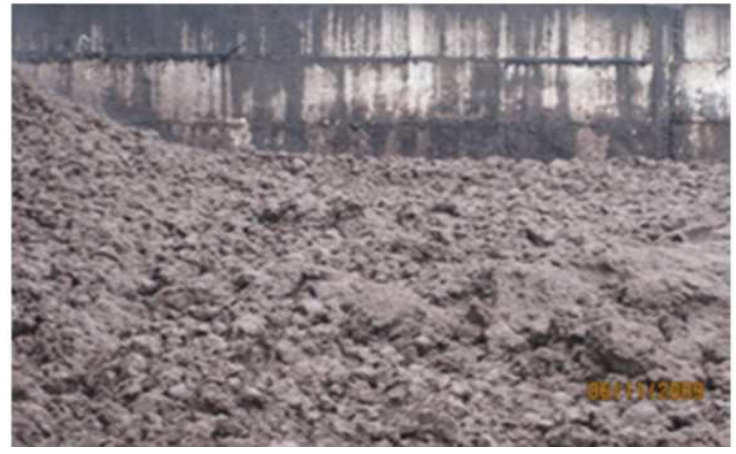

Fig. 1. Decanter cake from palm oil mill industry

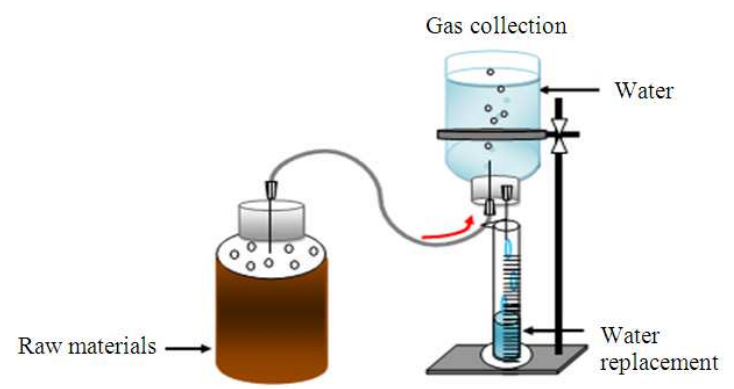

Fig. 2. Schematic of laboratory batch assessment of anaerobic digestion

In each run, the control reactors contained only the wastewater are set up in order to measure the gas production of seeding. For experiment III, each bottle is placed on an orbital shaker at $180 \mathrm{rpm}$ and incubated at $38 \pm 11^{\circ} \mathrm{C}$, until less than $5 \%$ of biogas production is detected.

\section{Experiment I}

In the first experiment, the decanter cake and rubber block wastewater are fed into the BMP reactors. This batch process is conducted under ambient temperature. Inoculum is taken from the methane fermentation stage of the UASB, frozen seafood industry in Songkhla province.

\section{Experiment II}

In the second experiment, the decanter cake and frozen seafood industry wastewater are fed into the BMP reactors. This batch process is conducted under ambient temperature. Inoculum is taken from the methane fermentation stage of the UASB, frozen seafood industry in Songkhla province.

\section{Experiment III}

In the third experiment, the decanter cake and frozen seafood industry wastewater are fed into the BMP reactors. This batch process is conducted under $38 \pm 1^{\circ} \mathrm{C}$ temperature (Mesophilic phase). Inoculum is taken from the methane fermentation stage of the UASB, frozen seafood industry in Songkhla province.

Each experiment consists of 6 reactors. Each reactor contains different amount of decanter cake. The detail of each reactor is following below:

$$
\begin{aligned}
& \mathrm{R} 1=\text { wastewater alone } 200 \mathrm{~mL} \\
& \mathrm{R} 2=\text { wastewater } 200 \mathrm{ml}+\text { decanter cake } 2 \mathrm{~g} \\
& \mathrm{R} 3=\text { wastewater } 200 \mathrm{ml}+\text { decanter cake } 5 \mathrm{~g} \\
& \mathrm{R} 4=\text { wastewater } 200 \mathrm{ml}+\text { decanter cake } 8 \mathrm{~g} \\
& \mathrm{R} 5=\text { wastewater } 200 \mathrm{ml}+\text { decanter cake } 10 \mathrm{~g} \\
& \mathrm{R} 6=\text { wastewater } 200 \mathrm{ml}+\text { decanter cake } 20 \mathrm{~g}
\end{aligned}
$$

\subsection{Gas Production}

The biogas is collected daily by the displacement of water to bottle. The biogas production is measured daily by inserting the needle of a gas syringe through the rubber septum and letting the biogas displace the wetted barrel of the syringe. The biogas is analyzed for methane using a Gas Chromatography (GC) analyzer (GC7890A, Agilent technology, USA) with Thermal Conductivity Detector (TCD).

\subsection{Calculating the Results}

The biogas production is recorded daily as the volume of biogas produced. The methane content is recorded as percentage of methane Equation 1:

$\mathrm{BMP}=\frac{\text { maximum } \text { cumulative methane gas }(\mathrm{ml})}{\mathrm{g} \text { COD removed }}$

\subsection{Monitoring Parameters}

During the experimental period, the amount of biogas in each reactor is monitored to evaluate the biogas yield.

\subsection{Analysis}

In all experiments, the following data are determined: biogas content, $\mathrm{pH}$, Total Solids (TS), COD and alkalinity. All analytical procedures are performed in accordance with APHA (1988).

\section{RESULTS}

\subsection{Raw Material Characteristics}

Table 1 presents the determined characteristics of selected potential raw materials for biogas production. 
Table 1. Characteristics of raw materials

\begin{tabular}{llrrr}
\hline Parameters & Units & \multicolumn{1}{c}{ DC } & \multicolumn{1}{c}{ SW } & RW \\
\hline pH & - & 4.94 & 5.31 & - \\
TS & $\%$ & 23.96 & 0.27 & 0.38 \\
TVS & $\%$ & 20.71 & 0.20 & 0.20 \\
COD & $\mathrm{mg} \mathrm{l}^{-1}$ (SW, RW) & $1,335.00$ & $4,000.00$ & $2,581.00$ \\
& g/kg dry (DC) & & & \\
Alkalinity & $\mathrm{mg} \mathrm{l}^{-1}$ as CaCO & & \\
VFA & $\mathrm{mg} \mathrm{l}^{-1}$ as CaCO & 40.00 & 598.00 & 420.00 \\
Moisture & $\%$ & 76.00 & 355.00 & 350.00 \\
content & & & - & - \\
\hline
\end{tabular}

*Remark: DC $=$ Decanter cake, $\mathrm{SW}=$ Seafood wastewater, $\mathrm{RW}$ $=$ Rubber block wastewater

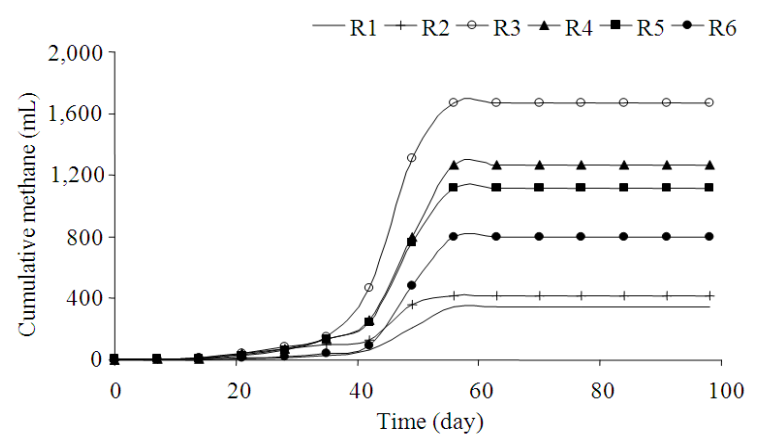

(a)

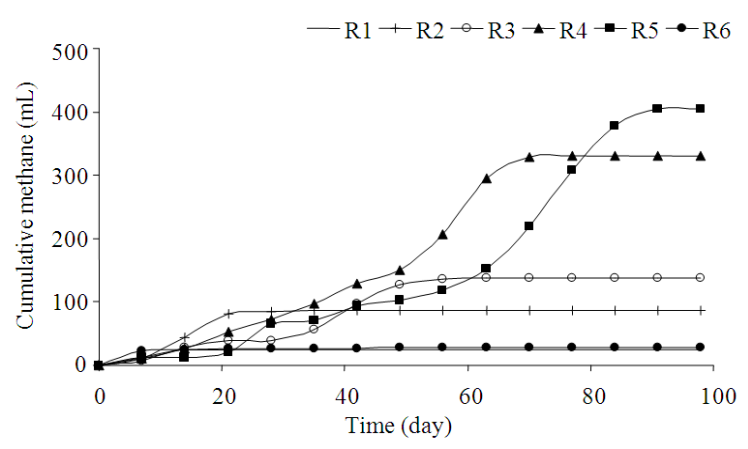

(b)

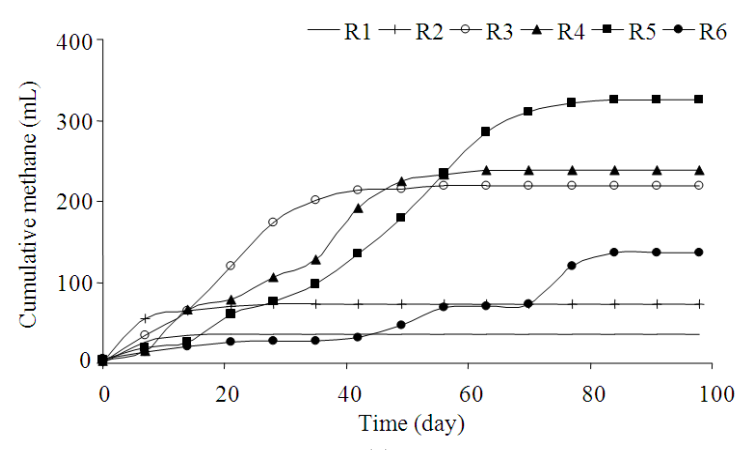

(c)

Fig. 3. Cumulative methane production (a) Experiment I, (b) Experiment II and (c) Experiment III
The decanter cake is characterized by high percentage of moisture $(>75 \%)$ and has a high biodegradability (Chavalparit et al., 2006; Yahya et al., 2010).

\subsection{Operation Results}

The results presented in this study are an average from the two repeated experiments. All three experiments perform for a period of 100 days. Figure 3 shows the BMP test data according to the various mixing ratio of co-digestion, types of wastewater and various amount of decanter cake.

The biogas and methane generation level off after 60 days indicating that the organic conversion is more or less completed. The maximum cumulative methane production is $380-1,673 \mathrm{~mL}$ under Experiment I, compared with 29-417 $\mathrm{mL}$ and 23-344 mL under Experiment II and Experiment III, respectively. However, the rates of methane production differ significantly according to the type of wastewater and various mixing ratio of co-digestion. The typical composition of methane is $55-75 \%$ (Karellas et al., 2010). The maximum percentage of methane gas obtained from all three experiments ranges from 50.6 to $66.7 \%$, which is in the typical range (Karellas et al., 2010).

Figure 4 shows the comparison of COD influent, COD effluent and COD removal in Experiment I and Experiment II (various type of wastewater). While, Fig. 5 shows the comparison of the same measures in Experiment II and Experiment III (various operated condition). The results of Experiment II and Experiment III show similar trend of COD removal. That is, the highest COD removal percentage is observed from R4. While, the highest COD removal percentage is observed from R3 in Experiment I.

Figure 6 shows the comparison of TS influent, TS effluent and TS removal in Experiment I and Experiment II (various the type of wastewater). Figure 7 shows the comparison of TS influent, TS effluent and TS removal in Experiment II and Experiment III (various the operated conditions). The highest TS removal percentage is indicated in the R5 in both Experiment II and Experiment III.

Figure 8 shows the biogas yield in Experiment I and Experiment II. This set compares the performance of the two different wastewater sources in co-digesting with the decanter cake under the same condition (without mixing and at ambient temperature). The clear tread from this graph is that the biogas yield values observed in all reactors of Experiment I (rubber block wastewater and decanter cake) are higher than those observed in all reactors of Experiment II (frozen seafood waster water and decanter cake). 
Thaniya Kaosol and Narumol Sohgrathok / American Journal of Agricultural and Biological Sciences 8 (1): 67-74, 2013

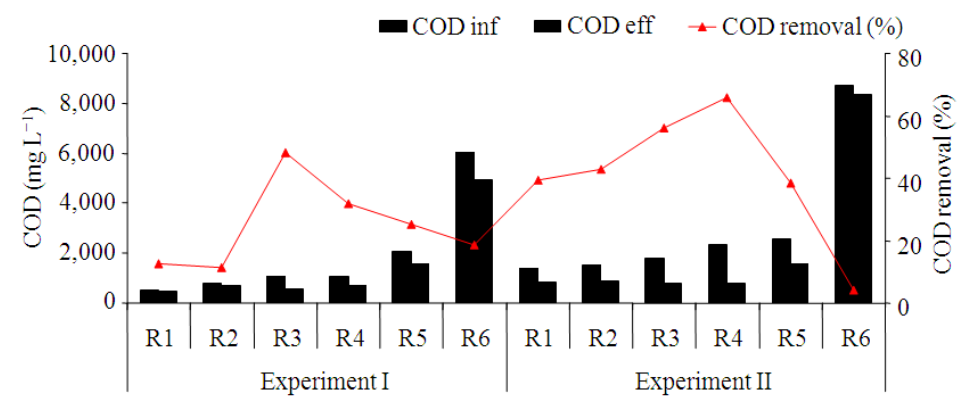

Fig. 4. Comparison of COD influent, COD effluent and COD removal in Experiment I and Experiment II

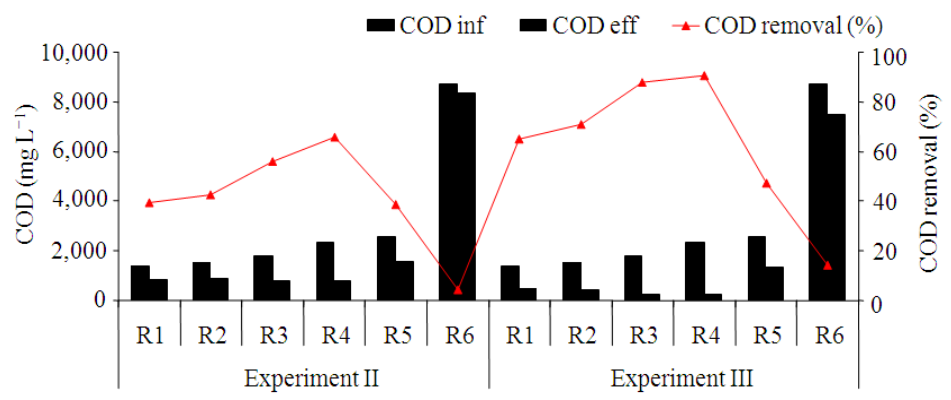

Fig. 5. Comparison of COD influent, COD effluent and COD removal in Experiment II and Experiment III

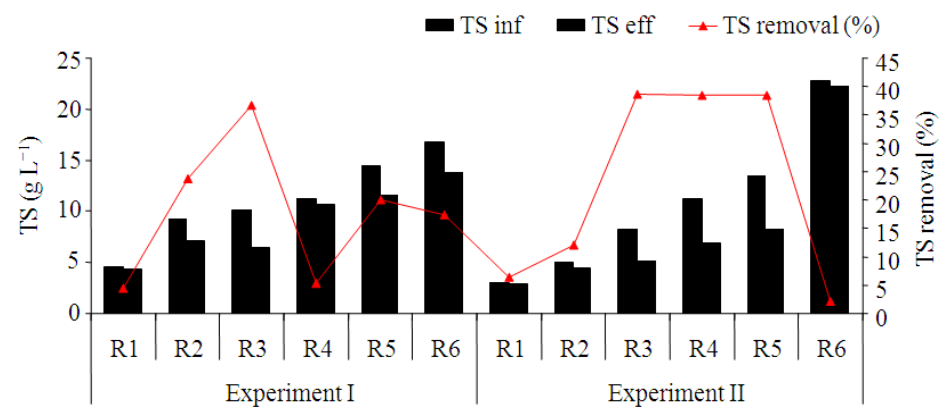

Fig. 6. Comparison of TS influent, TS effluent and TS removal in Experiment I and Experiment II

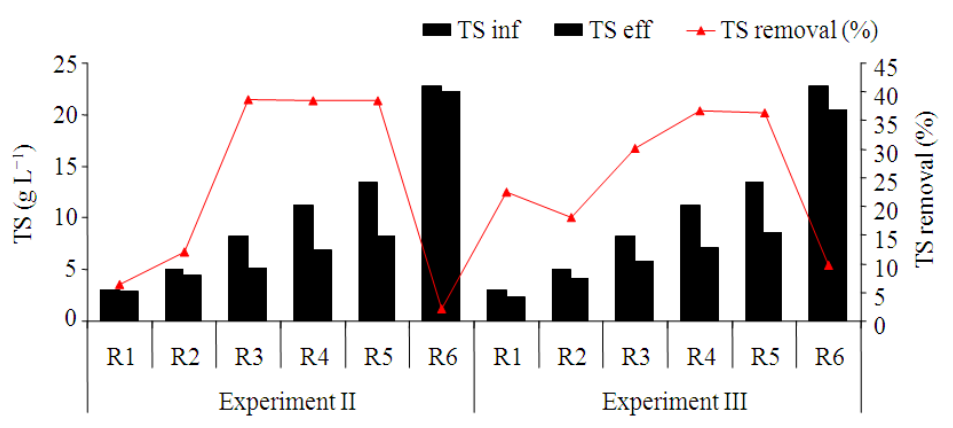

Fig. 7. Comparison of TS influent, TS effluent and TS removal in Experiment II and Experiment III 


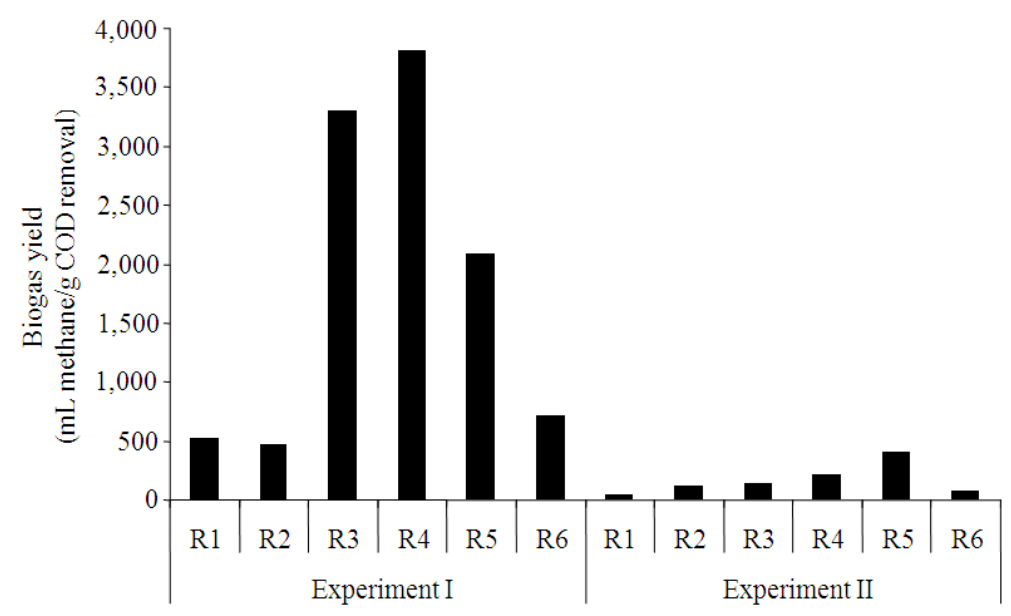

Fig. 8. Biogas yield in Experiment I and Experiment II

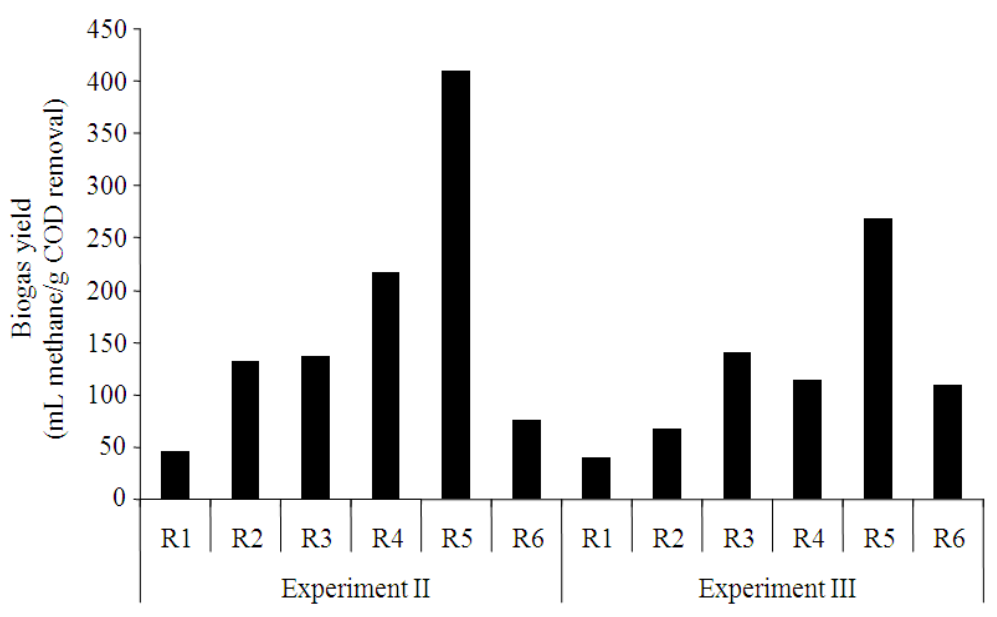

Fig. 9. Biogas yield in Experiment II and Experiment III

Figure 9 shows the biogas yield in Experiment II and Experiment III. This set compares the effect of different temperatures by using the ambient temperature in Experiment II and the mesophilic temperature in Experiment III. Both experiments use the same codigestion between frozen seafood wastewater and decanter cake. The highest biogas yield is observed in R5 in both experiments.

\section{DISCUSSION}

The ultimate biogas yield of organic substrates, such as the potential extent and rate of conversion of biomass and wastes to methane, can be determined using the BMP assay. The strong characteristic of the BMP method is its quickness and low cost. The methane yield is based from $\mathrm{g}$ COD removed.

\subsection{Effects of the Type of Wastewater}

Experiment I and Experiment II are carried out in batch tests and methane production is followed for 100 days (Fig. 3). The biogas production started immediately in all reactors and reached its maximum cumulative methane value after 60 days. After 60 days of observations, the biogas and methane production tend to decrease. However, this phenomenon is predictable due to the stationary phase of microorganism growth (Castillo et al., 1995). A wide range of co-digestion with decanter cake and various wastewaters has been considered as potential sources for methane production. 
Increasing amount of decanter cake in the mixture ratio can improve the biogas potential production. However, too large amount decanter cake can cause the biogas potential production to decrease because the microorganisms in the system can not consume all the food. Rubber block wastewater shows higher methane production and biogas yield than frozen seafood wastewater for co-digestion with decanter cake (Fig. 3 and 8). These results may be concluded that the rubber block wastewater is an easily biodegradable substrate for co-digestion process.

According to the experimental results, if the type of raw materials changed, the biogas yield is estimated to significantly increase. By using the frozen seafood wastewater in the raw materials, the maximum biogas yield increases 8 times (R1 and R5 in Experiment II). By using the rubber block wastewater in the raw materials, the maximum biogas yield increases 7.6 times (R1 and R4 in Experiment I). These increasing values mean that more organic has to be handled in the biogas experiment and as digestate.

As to anaerobic digestion, the biogas yield can be affected by the digestion technology (co-digestion) and type of raw materials. The maximum methane percentage of the biogas obtained from all the experiment is ranged from $50.6 \%$ to $66.7 \%$. Such values are in the range reported in the literature depending on the biomass type (60-75\%) (Nayono et al., 2010). All the reactors of Experiment I have shown biogas yield values higher than those observed from using frozen seafood wastewater in Experiment II.

The biogas yield is range 500-3,809 and 58-422 $\mathrm{mL}$ methane/g COD removal for Experiment I and II (Fig. 8), respectively. The highest biogas yield is 3,809 $\mathrm{mL}$ methane/g COD removal.

The best results are obtained when the co-digestion is done with the rubber block wastewater. Improved codigestion performance in terms of waste stabilization is achieved. The highest methane yield value of 3,809 mL methane/g COD removal is shown in R4 of Experiment I. The best result is displayed by R4 in Experiment I.

In this study, a large variation in biogas yield values is observed. This may cause by the variation in composition of the raw materials and the digestion conditions. However, the co-digestion of decanter cake with rubber block wastewater provides the high methane content biogas.

\subsection{Effects of the Temperature and Mixing for Operated Condition}

Similar to the first set of experiments, Experiment II and Experiment III are carried out in batch with 100-day methane production monitoring (Fig. 3). Immediately, the biogas production started in all reactors. The production reached its maximum cumulative methane value after 60 days. However, the biogas and methane production does not show any significant increment after the 60-day mark. This phenomenon is predicted due to the stationary phase of the microorganism growth (Castillo et al., 1995). Many researches have showed the methane yields at the thermophilic range $\left(55-65^{\circ} \mathrm{C}\right)$ were higher than those at the mesophilic range $\left(30-40^{\circ} \mathrm{C}\right)$ in batch studies (Gunaseelan, 1997; Holm-Nielsen et al., 2009). In this study, no significant difference in biogas production and methane yield in Experiment II and Experiment III were noticed. The biogas yield is 58- 422 and 23-344 $\mathrm{ml}$ methane/g COD removal for Experiment II and Experiment III, respectively (Fig. 9). For the stoichiometric conversion, the methane production is directly related to organic degradation; $395 \mathrm{~mL}$ methane equals $1 \mathrm{~g}$ COD removal (Speece, 1996). The temperature of digestion condition can not improve the potential of biogas production because Thailand is a tropical country. The temperature is almost $25-28^{\circ} \mathrm{C}$ which is suitable for anaerobic bacteria. However, the R5 (wastewater $200 \mathrm{~mL}$ and decanter cake $10 \mathrm{~g}$ ) shows the highest of the methane yield and biogas production in both experiments.

The biogas yield shows no significant difference in the mixing and incubated at $38 \pm 1^{\circ} \mathrm{C}$ between the Experiment II and Experiment III (Fig. 9). The methane yield is more or less similar in all reactors of the Experiment II and Experiment III.

Nevertheless, the co-digestion between decanter cake and various wastewaters should be taken into consideration, for scale-up purposes, in operating at industrial scale with continuous system.

\section{CONCLUSION}

The aim of this study is to analyze the effect of the biogas yield performance in biogas production using various parameters. The three main parameters in this study are the raw materials, the mixing and the temperature. The effect of wastewater and solid content to biogas yield was studied by performing the BMP batch experiments. There are large variations among the raw materials studied regarding degradability. These high biogas yields are obtained only by co-digestion with other raw materials.

The co-digestion of decanter cake with wastewater has a stimulatory effect on methane gas productions and methane percentages in BMP test. The co-digestion of decanter cake with rubber block wastewater of reactor 4 (R4 of Experiment I) gave the highest biogas yield at 3,809 mL methane/g COD removal. This result indicates that co-digestion processes at a higher efficiency than that of wastewater alone. This study shows that anaerobic co- 
digestion of decanter cake with wastewater is a feasible process in the stabilization of the waste and in the increasing potential of wastewater to biogas production.

\section{ACKNOWLEDGEMENT}

Authors are grateful to the annual government statement of expenditure 2011, National Research Council of Thailand (NRCT), Thailand for the financial support for carrying out this study.

\section{REFERENCES}

Angelidaki, I., M. Alves, D. Bolzonella, L. Borzacconi and J.L. Campos et al., 2009. Defining the Biomethane Potential (BMP) of solid organic wastes and energy crops: A proposed protocol for batch assays. Water Sci. Technol., 59: 927-934. DOI: 10.2166/wst.2009.040

APHA, 1988. Standard Method for the Examination of Water and Wastewater. 1st Edn., American Public Health Association, Washington, D.C., ISBN-10: 0875530788, pp: 161.

Castillo, R.T., P.L. Luengo and J.M. Alvarez, 1995. Temperature effect on anaerobic digestion of bedding straw in a one phase system at different inoculum concentration. Agric. Ecosyst. Environ., 54: 55-66. DOI: 10.1016/0167-8809(95)00592-G

Chavalparit, O., W.H. Rulkens, A.P.J. Mol and S. Khaodhair, 2006. Options for environmental sustainability of the crude palm oil industry in Thailand through enhancement of industrial ecosystems. Environ. Dev. Sustain., 8: 271-287. DOI: $10.1007 / \mathrm{s} 10668-005-9018-\mathrm{z}$

Gunaseelan, V.N., 1997. Anaerobic digestion of biomass for methane production: A review. Biomass Bioener., 13: 83-114. DOI: 10.101016/S09619534(97)00020-2

Holm-Nielsen, J.B., T. Al Seadi and P. OleskowiczPopiel, 2009. The future of anaerobic digestion and biogas utilization. Bioresource Technol., 100: 54785484. DOI:10.1016/j.biortech.2008.12.046

Karellas, S., I. Boukis and G. Kontopoulos, 2010. Development of an investment decision tool for biogas production from agricultural waste. Renew. Sustain. Energy Rev., 14: 1273-1282. DOI: 10.1016/j.rser.2009.12.002

Kirkeby, J.T., H. Birgisdottir, T.L. Hansen, T.H. Christensen and G.S. Bhander et al., 2006. Evaluation of environmental impacts from municipal solid waste management in the municipality of Aarhus. Denmark EASEWASTE, Waste Manage Res., 24: 16-26. DOI: $10.1177 / 0734242 \times 06062598$
Koblitsch, P., C. Pfeifer and H. Hofbauer, 2008. Catalytic steam reforming of model biogas, Fuel, 87: 701-706. DOI: 10.1016/j.fuel.2007.06.002

Nayono, S.E., C. Gallert and J. Winter, 2010. Codigestion of press water and food waste in a biowaste digester for improvement of biogas production. Bioresource Technol., 101: 6987-6993. DOI: 10.1016/j.biotech.2010.03.123

Owen, W.F., D.C. Stuckey, J.B. Healy Jr., L.Y. Young and P.L. McCarty, 1979. Bioassay for monitoring biochemical methane potential and anaerobic toxicity. Water Res., 13: 485-492. DOI: 10.1016/0043-1354(79)90043-5

Paepatung, N., A. Nopharatana and W. Songkasiri, 2009. Bio-methane potential of biological solid materials and agricultural wastes. Asian J. Energy Environ., 10: 19-27.

Parawira, W., M. Murto, S. Read and B. Mattiasson, 2007. A study of two-stage anaerobic digestion of solid potato waste using reactors usnder mesophilic and thermophilic conditions. Environ. Technol., 28: 1205-1216. DOI: 10.1080/09593332808618881

Pipatmanomai, S., S. Kaewluan and T. Vitidsant, 2009. Economic assessment of biogas-to-electricity generation system with $\mathrm{H}_{2} \mathrm{~S}$ removal by activated carbon in small pig farm. Applied Energy, 86: 669674. DOI: $10.1016 /$ j.apenergy.2008.07.007

Sosnowski, P., A. Wieczorek and S. Ledakowicz, 2003. Anaerobic co-digestion of sewage sludge and organic fraction of municipal solid wastes. Adv. Environ. Res., 7: 609-616. DOI: 10.1016/S10930191(02)00049-7

Speece, R.E., 1996. Anaerobic Biotechnology for Industrial Wastewaters. 1st Edn., Archae Press, Nashville, Tenn, ISBN-10: 0965022609, pp: 394.

Truong, L.V.A. and N. Abatzoglou, 2005. A $\mathrm{H}_{2} \mathrm{~S}$ reactive adsorption process for the purifiction of biogas prior to its use as a bioenergy vector. Biomass Bioener., 29: 142-151. DOI: 10.1016/j.biombioe.2005.03.001

Yadvika, Santosh, T.R. Sreekrishnan, S. Kohli and V. Rana, 2004. Enhancement of biogas production from solid substrates using different techniques-a review. Bioresource Technol., 95: 1-10. DOI: 10.1016/j.biortech.2004.02.010

Yahya, A., C.P. Sye, T.A. Ishola and H. Suryanto, 2010. Effect of adding palm oil mill decanter cake slurry with regular turning operation on the composting process and quality of compost from oil palm empty fruit bunches. Bioresource Technol., 101: 87368741. DOI: 10.1016/j.biortech.2010.05.073

Yen, H.W. and D.E. Brune, 2007. Anaerobic codigestion of algal sludge and waste paper to produce methane. Bioresource Technol., 98: 130-134. DOI: 10.1016/j.biortech.2005.11.010 